\title{
A Review On The Anti-Inflammatory Activity Of Hesperidin, A Bioflavonoid Synthesized By Citrus Fruits
}

\section{Ganesh Chandra Jagetia}

10 Maharana Pratap Colony1, Sector-13, Hiran Magri,Udaipur-313002, India.

Corresponding Author: Prof. Ganesh Chandra Jagetia10, Maharana Pratap Colony, Sector-13, Hiran Magri, Udaipur-313002, India, Email: gc.jagetia@gmail.com

Received date: May 05 , 2018; Accepted date : July 18, 2018; Published date: July 30, 2018.

Citation this Article : Igor Klepikov, A Review on the Anti-inflammatory activity of hesperidin, a bioflavonoid synthesized by citrus fruits. J.Immunology and Inflammation Diseases Therapy . Doi: http://dx.doi.org/ 10.31579/1.10037.

Copyright : (c) 2018 Igor Klepikov. This is an open-access article distributed under the terms of The Creative Commons Attribution License, which permits unrestricted use, distribution, and reproduction inany medium, provided the original author and source are credited.

\begin{abstract}
Inflammation is an all-pervasive phenomenon and it is triggered as a countermeasure against pathogenic attack, harmful stimuli and damage to the body tissues. Generally, inflammation peters out once its cause gets terminated. However, persistence of (chronic) inflammation is harbinger of almost all diseases, which that inflammation needs to be tamed to ward off against its harmful effects. The natural products may be good candidates to suppress inflammation. Hesperidin, a bioflavonoid consumed regularly by humans is attributed to possess several medicinal properties including free radical scavenging and anti-inflammatory. This review mainly dwells on its anti-inflammatory property in various study systems. The regular use of hesperidin may be encouraged to stall inflammation related health disorders in humans.
\end{abstract}

\section{Key words}

Inflammation; anti-inflammatory activity; hesperidin; cytokines; free radicals.

Short title

Anti-inflammatory activity of hesperidin

\section{Inflammation}

The term 'inflammation' is derived from the Latin word "inflammare", which means to burn. The inflammation is an allpervasive phenomenon, which is triggered by body tissues against the pathogen attack, harmful stimuli and tissue injury [1]. Inflammation is an innate and adaptive immune response against microbes and parasites that initiate deleterious changes in the tissues [2]. The inflammation is characterized by redness, swelling, heat, pain and loss of function and it was first described by Aulus Cornelius Celsus an encyclopaedist in the First century AD [3]. The inflammation is also a response triggered against the disruption of tissue homeostasis [4].

Inflammation is mainly responsible for the identification and destruction of its source, isolate the source of disturbance, abolish the damaged tissue and restore the homeostasis of the damaged tissue [4,5]. The inflammation is mediated by the concerted action of leukocytes, especially the neutrophils, monocytes and macrophages [5]. These cells secrete a host of factors including serotonin, histamine, eicosanoids, several cytokines, chemokines and plasma derived factors, which dilate the blood vessels and increase their permeability [6]. The inflammatory responses are two types acute and chronic and different mechanisms are involved in their onset [7].

The inflammation is indicted in almost all health disorders. The inflammatory responses are eliminated once the cause of inflammation is terminated. However, sustained inflammation is the major cause of several diseases including diabetes, atherosclerosis, rheumatoid arthritis, hay fever, ischemic heart diseases, leprosy, neurodegenerative disorders, ischemia reperfusion injury, asthma, celiac diseases, tuberculosis, syphilis, inflammatory bowel disease, nephritis, vascularitis, numerous auto-immune diseases and cancer $[6,8]$.
The fact is that any or all health disorders have a direct or indirect link with inflammation. Presently aspirin, non-steroidal anti-inflammatory drugs (NSAIDs) and anticytokine therapy are used to control inflammation [9]. The NSAIDs trigger undesirable adverse side effects on gastric mucosa, liver, heart, kidney, and bronchus [10,11]. This indicates the need of safe and non-toxic alternatives to tame inflammation. The natural products may of great help to reduce the chronic inflammation and inhibit the inflammatory disorder in human beings. Hesperidin, a citrus bioflavonoid which is in regular use as an orange juice may be useful to suppress the inflammation. This review discusses the anti-inflammatory activity of hesperidin a secondary metabolite synthesized mainly by citrus plants.

\section{Hesperidin Actions}

The use of dietary ingredients to reduce inflammation or treat inflammation related disorder is an attractive position. The hesperidin (Hesperetin 7-O-rutinoside or Hesperitin-7-rhamnoglucoside) is a bioflavonoid synthesized mainly by many citrus plants as a secondary metabolite, and it is abundantly present in the fruit juices and rinds of these plants [12]. The main function of the hesperidin is to protect citrus plants against fungal and bacterial intrusions [13]. The sweet oranges (Citrus sinensis), tangelos and pulpy orange juice contain the highest amount of hesperidin than the orange juice that has no pulp [14]. Generally, 470-761 mg of hesperidin is present in one litre of orange juice [15]. The hesperidin is converted into its aglycone, hesperitin in the colon by the action of intestinal bacteria, which is subsequently degraded or absorbed [16]. Hesperidin aids in absorption of vitamin $\mathrm{C}$ and increases capillary (blood vessels) permeability. It helps to improve hypertension in humans, protects against haemorrhages, infections, heals ruptured capillaries and connective tissues [17]. 
The analgesic, antiallergenic, antimicrobial, anticancerous, antiinflammatory, antihypotensive and vasodilating activities of hesperidin have been reported in different study systems [18-21]. The drinking of $500 \mathrm{ml}$ orange juice daily for four weeks consecutively has been reported to trigger the activation of 3422 genes in humans, whereas hesperidin intake in a similar fashion activated only1819 genes in humans [22]. Hesperidin has been reported to be active against atherogenesis, apoptosis, arthritis, infection, Herpes simplex virus infection, oxidative stress, neurotoxicity, inflammatory bowel disease, platelet and erythrocyte aggregation [23-33]. The hesperidin scavenged free various radicals in vitro and increased the wound healing of irradiated wounds. Oral administration of hesperidin was found to be non-toxic up to a dose of $2 \mathrm{~g} / \mathrm{kg}$ body weight in mice [34,35]. Earlier sub chronic administration of 5\% hesperidin for 13 weeks has been reported to be non-toxic in mice [36]. These reports suggest that hesperidin is a multifaceted molecule and possess several activities.

\section{Free radical scavenging}

The free radicals are one of the important mediators of inflammation and the free radical scavenging activity of hesperidin has been studied in vitro. The treatment with different concentrations of hesperidin suppressed the production of ${ }^{\bullet} \mathrm{OH}$ and $\mathrm{O}_{2}{ }^{\bullet-}$ radicals in a concentration dependent manner and a maximum scavenging of both these radicals was recorded at $500 \mu \mathrm{g} / \mathrm{ml}$. However, hesperidin did not scavenge DPPH radical up to a concentration of $100 \mu \mathrm{g} / \mathrm{ml}$, and a further increase in its concentration led to a concentration dependent rise in DPPH scavenging up to $500 \mu \mathrm{g} / \mathrm{ml}$. The total antioxidant activity using ABTS revealed concentration dependent scavenging of ABTS $^{\bullet+}$ radicals up to $200 \mu \mathrm{g} / \mathrm{ml}$ hesperidin, which plateaued thereafter. The nitric oxide $\left(\mathrm{NO}^{\bullet}\right)$ radicals were also suppressed by hesperidin as it showed a dose dependent scavenging of $\mathrm{NO}^{\bullet}$ up to 60 $\mu \mathrm{g} / \mathrm{ml}$, which reached an almost steady state thereafter. However, the maximum scavenging of nitric oxide was observed at $400 \mu \mathrm{g} / \mathrm{ml}$ [34].

\section{Anti-Inflammatory Activity}

The anti-inflammatory activity of hesperidin was studied in carrageenan-induced rat paw edema, where treatment of rats with 50 and $100 \mathrm{mg} / \mathrm{kg}$ body weight (b. wt.) of hesperidin sub cutaneously (S.C.) reduced the carrageenan-induced paw oedema by 47 and 63\%, respectively, within $5 \mathrm{~h}$ of its administration. Similarly, treatment of rats with $100 \mathrm{mg} / \mathrm{kg}$ hesperidin alleviated the dextran induced rat paw oedema by $33 \%$, without influencing the histamine-induced paw oedema. Hesperidin suppressed the carrageenan-induced pleurisy, where it reduced the volume of exudate and the number of migrating leucocytes by 48 and $34 \%$, respectively of control values. Administration of mice with $100 \mathrm{mg} / \mathrm{kg} \mathrm{b}$. wt. hesperidin s. c. reduced acetic acid-induced abdominal constriction by $50 \%$, however, did not affect the tail flick response [37].

Treatment of mice with $100,200,300$ and $400 \mathrm{mg} / \mathrm{kg} \mathrm{b}$. wt. hesperidin suppressed the induction of xylene induced ear edema by $26.03 \%$ (10.34 $\pm 1.05 \mathrm{mg}), 34.54 \%(9.15 \pm 1.09 \mathrm{mg}), 47.21 \%(7.38 \pm 1.2$ $\mathrm{mg})$ and $43.63 \%(7.88 \pm 0.63 \mathrm{mg})$, respectively in mice. Similarly, administration of mice with $100,200,300$ and $400 \mathrm{mg} / \mathrm{kg} \mathrm{b}$. wt. hesperidin significantly reduced the formalin-induced paw edema indicating its anti-inflammatory potential [38].

A study on the of anti-inflammatory activity on the rat air pouch model exhibited that hesperidin treatment of rat pouch injected with carrageenan reduced the carrageenan-induced rise in the lipid peroxidation, glutathione, nitrite and the activities of superoxide dismutase and catalase and TNF- $\alpha$ in the air pouch homogenate. Carrageenan injection into the air pouch induced edema, marked by the enlargement of the pouch wall and the infiltration with neutrophils, macrophages and lymphocytes. Treatment of $50 \mathrm{mg} / \mathrm{kg}$ hesperidin S.C. reversed all these changes and the inflammatory cells including neutrophils, macrophages and lymphocytes were conspicuous by their absence indicating that it has blocked the inflammatory response [39].
Treatment of rats with 10 or $25 \mathrm{mg} / \mathrm{kg} \mathrm{b}$. wt. hesperidin exerted antiinflammatory effect in the trinitrobenzenesulfonic acid induced colitis. It reduced the activity of myeloperoxidase and increased the glutathione contents in the colitic rats [40].

Treatment of 100 and $200 \mathrm{mg} / \mathrm{kg} \mathrm{b}$. wt. hesperidin to high fat diet fed LDL receptor deficient $\left(\mathrm{LDLr}^{-/}\right)$mice model of atherosclerosis resulted in the inhibition of hepatic steatosis, atherosclerotic plaque area and macrophage foam cell formation. The hesperidin treatment resulted in the down-regulated expressions of acetyl coenzyme A carboxylase alpha $(\mathrm{ACC} \alpha)$ and fatty acid synthase (FAS) in the liver. Hesperidin also increased the expression of hepatic ATP-binding cassette transporters G8 (ABCG8), macrophage ATP-binding cassette transporters A1 (ABCA1) and $\mathrm{G} 1$ (ABCG1) indicating that hesperidin alleviated the inflammation in $\mathrm{LDLr}^{-/-}$mice and reduced atherosclerosis [41].

The study of anti-inflammatory activity of hesperidin on lipopolysaccharide (LPS)-induced lung inflammation revealed that administration of $200 \mathrm{mg} / \mathrm{kg}$ b. wt. of hesperidin orally downregulated the LPS-induced expression of various cytokines including TNF- $\alpha$, IL-1 $\beta$, IL6 , KC, MIP-2, MCP-1, and IL-12 coupled with the elevated production of IL-4, IL-10. The hesperidin administration reduced the total leukocyte counts; nitric oxide production, iNOS expression in the lungs of LPS treated mice. Hesperidin treatment inhibited the expression of IL- 8 in cultured A549 cells and THP-1 cells, whereas the proinflammatory cytokines including TNF- $\alpha$, IL- $1 \beta$, and IL- 6 were suppressed in THP-1 cells only. The expression of ICAM-1 and VCAM-1 was inhibited in A549 cells treated with hesperidin [42]. Hesperidin also inhibited the LPS induced secretion and gene expression of NO, TNF- $\alpha$, IL-1b, and IL- 6 in BV2 microglial cells [43].

Myocardial infarction is an inflammatory disease and hesperidin administration into the acute myocardial infarction mice markedly depleted the myocardial infarction area, reduced the heart weight/body weight ratio and activity of creatine kinase-MB. Hesperidin treatment also resulted in a decline in the TNF- $\alpha$, IL-1 $\beta$, IL-6, MCP-1, ICAM-1, lipid peroxidation and activities of catalase, SOD and caspase-3/9 in mice model of acute myocardial infarction. The expression of p53 and Bax/Bcl-2, was suppressed by hesperidin treatment followed by the induction of peroxisome proliferator-activated receptor- $\gamma$ (PPAR- $\gamma$ ) in mice with acute myocardial infarction [44].

Bioregulatory molecule nitric oxide plays a crucial role in instigating inflammatory responses and is secreted by neutrophils and macrophages $[45,46]$. Hesperidin treatment has been reported to reduce the radiation induced secretion of $\mathrm{NO}$ estimated as nitrate and nitrite in the regenerating wound of mice at 12 days post-irradiation indicating the antiinflammatory activity of hesperidin [35].

A study using hesperidin methyl chalcone at $3-100$ or $30 \mathrm{mg} / \mathrm{kg}$ b. wt. intraperitoneally in male Swiss mice inhibited acetic acid- and phenyl-p-benzoquinone-induced writhing. It also suppressed capsaicin-, complete Freund's adjuvant- and formalin-induced paw flinching and licking. Hesperidin methyl chalcone did attenuate carrageenan-, capsaicinand complete Freund's adjuvant -induced mechanical and thermal hyperalgesia. The exploration of molecular mechanisms revealed that hesperidin methyl chalcone alleviated carrageenan-induced TNF- $\alpha$, IL- $1 b$, IL-6, and IL-10 production, oxidative stress and NF- $\mathrm{KB}$ activation. Hesperidin methyl chalcone did not induce gastric or hepatic injury in a 7 days treatment protocol [47].

\section{Mechanism of action}

The exact mechanism of action to suppress the inflammatory responses by hesperidin is not known. However, the anti-inflammatory action of hesperidin may be mediated by the attenuation of transcriptional activation of $\mathrm{NF}-\kappa \mathrm{B}$, and $\mathrm{COX}-\mathrm{II}$, which may down modulate the expression of TNF- $\alpha$, IL-1 $\beta$, IL-6, ICAM-1, MIP-2, MCP-1, iNOS, VCAM-1 and IL-12 (Figure 1). The hesperidin has been reported to subdue the expression of NF- $\kappa B$, and COX-II and TNF- $\alpha$, IL-1 $\beta$, IL-6, ICAM-1, MIP-2, MCP-1, iNOS, VCAM-1 and IL-12 earlier (Figure 1) $[42,44,48,49]$. 

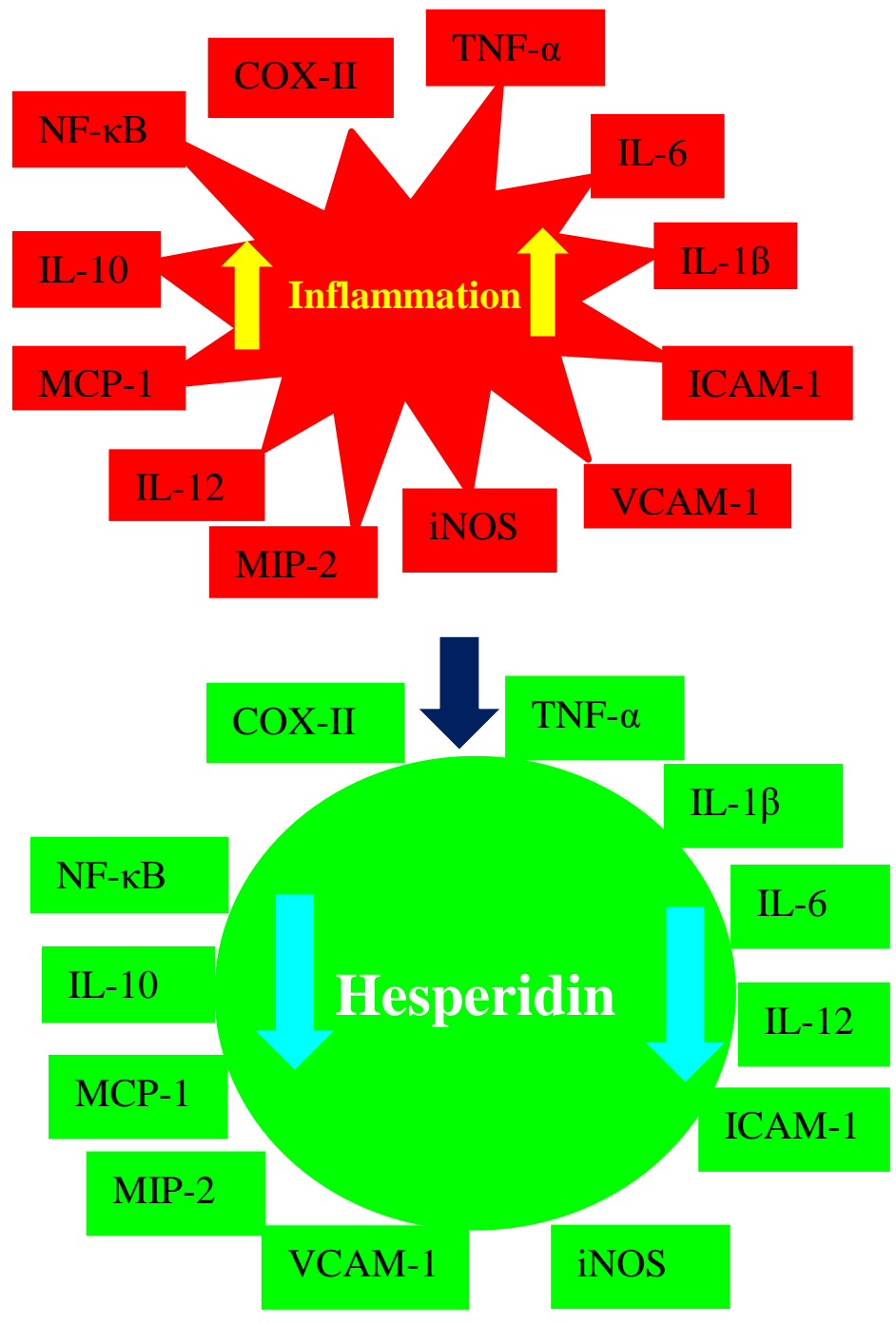

Figure 1: Mechanism of action of anti-inflammatory activity of hesperidin.

\section{Conclusions}

The inflammation is a defence mechanism elicited in response to microbial attack, harmful stimuli and tissue injury. However, prolonged inflammation is the major cause of almost all health disorders including diabetes, cardiovascular, neurological, gastrointestinal, hepatic and kidney disorders and cancer. Therefore, it is necessary to suppress the acute and chronic inflammation to keep the human health in good condition. The hesperidin present in the citrus fruits and their rinds has shown potential as an antiinflammatory agent as indicated by its ability to inhibit the generation of various free radicals and numerous cytokines including NF- $\kappa \mathrm{B}$, and COX-II, TNF- $\alpha$, IL-1 $\beta$, IL-6, ICAM-1, MIP-2, MCP-1, iNOS, ICAM1 , VCAM-1 and IL-12. Since hesperidin is present in various citrus fruits it can be used to inhibit inflammatory disorders as a functional food medicine in humans. Moreover, it is non-toxic, used regularly as orange juice and will be easily acceptable. Therefore, intake of citrus fruit juices/hesperidin may be encouraged to keep humans healthy and ptotect themselves from inflammatory disorders.

\section{Acknowledgements}

I wish to acknowledge the constant support, encouragement, and patience of my wife Mrs. Mangla Jagetia during this work.

\section{Conflict of interest statement}

The author does not have any Conflict of Interest statement to declare.

\section{References}

1. Ashley NT, Weil ZM, Nelson RJ. Inflammation: mechanisms, costs, and natural variation. Annual Review of Ecology, Evolution, and Systematics. 2012;43: 385-406.

2. Simon AK, Hollander GA, McMichael A. Evolution of the immune system in humans from infancy to old age. Proc. R. Soc. 2015; 282(1821):20143085.

3. Tedgui A. Focus on inflammation. Arteriosclerosis, thrombosis, and vascular biology. 2011; 31(5):958-959.

4. Medzhitov R. Origin and physiological roles of inflammation. Nature 2008; 454(7203):428-435.

5. Soehnlein O, Lindbom L. Phagocyte partnership during the onset and resolution of inflammation. Nature Rev Immunol. 2010;10(6):427-439.

6. Markiewski MM, Lambris JD. The role of complement in inflammatory diseases from behind the scenes into the spotlight. The American journal of pathology. 2007;171(3):715-727.

7. Serhan CN, Dalli J, Colas RA, Winkler JW, Chiang N. Protectins and maresins: New pro-resolving families of mediators in acute inflammation and resolution bioactive metabolome. Biochim. Biophys. Acta (BBA) Mol. Cell Biol. Lipids 2015; 1851: 397413.

8. Scrivo R, Vasile M, Bartosiewicz I, Valesini G. Inflammation as "common soil" of the multifactorial diseases. Autoimmun Rev. 2011;10(7):369-734.

9. Dinarello CA. Anti-inflammatory agents: present and future. Cell. 2010;140(6):935-950.

10. Wallace JL, Vong L (2008) NSAID-induced gastrointestinal damage and the design of GI-sparing NSAIDs. Curr Opin Investig Drugs 9(11):1151-1156.

11. Lapeyre-Mestre M, Grolleau S, Montastruc JL. Adverse drug reactions associated with the use of NSAIDs: a case/noncase analysis of spontaneous reports from the French pharmacovigilance database 2002-2006. Fundam Clin Pharmacol. 2013;27(2):223-230

12. Iglesias DJ, Cercós M, Colmenero-Flores JM, Naranjo MA, Ríos G, Carrera E, Ruiz-Rivero O, Lliso I, Morillon R, Tadeo FR, Talon M. Physiology of citrus fruiting. Brazil J Plant Physiol. 2007;19(4):333-362.

13. Del Rio JA, Gomez P, Baidez AG, Arcas MC, Botia JM, Ortuno A. Changes in the levels of polymethoxyflavones and flavanones as part of the defense mechanism of Citrus sinensis (cv. Valencia Late) fruits against Phytophthora citrophthora. J Agr Food Chem. 2004; 52(7):1913-1917.

14. Nogata Y, Sakamoto K, Shiratsuchi H, Ishii T, YANO M, Ohta H. Flavonoid composition of fruit tissues of citrus species. Biosci Biotechnol Biochem. 2006; 70(1):178-192.

15. D'Archivio M, Filesi C, Di Benedetto R, Gargiulo R, Giovannini C, Masella R. Polyphenols, dietary sources and bioavailability. Ann Inst Super Sanita. 2007; 43(4):348-361.

16. Jin MJ, Kim U, Kim IS, Kim Y, Kim DH, Han SB, Kim DH, Kwon OS, Yoo HH. Effects of gut microflora on pharmacokinetics of hesperidin: a study on non-antibiotic and pseudo-germ-free rats. J Toxicol Environm Hlth, Part A. 2010; 73(21-22):1441-1450.

17. Ameer B, Weintraub RA, Johnson JV, Yost RA, Rouseff RL. Flavanone absorption after naringin, hesperidin, and citrus administration. Clin Pharmacol Therapeut. 1996; 60(1):34-40.

18. Miyagi Y, Om AS, Chee KM, Bennink MR. Inhibition of azoxymethane-induced colon cancer by orange juice. Nutr Cancer. 2000;36(2):224-229.

19. Ahmadi A, Shadboorestan A, Nabavi SF, Setzer WN, Nabavi SM. The role of hesperidin in cell signal transduction pathway for the prevention or treatment of cancer. Curr Med Chem. 2015; 22(30):3462-71. 
20. Dobiaš L, Petrová M, Vojtko R, Kristová V. Long-term treatment with hesperidin improves endothelium-dependent vasodilation in femoral artery of spontaneously hypertensive rats: The involvement of NO-synthase and $\mathrm{Kv}$ channels. Phytother Res. 2016; 30(10):1665-71.

21. Iranshahi M, Rezaee R, Parhiz H, Roohbakhsh A, Soltani F. Protective effects of flavonoids against microbes and toxins: The cases of hesperidin and hesperetin. Life Sci. 2015; 137:125-132.

22. Milenkovic D, Deval C, Dubray C, Mazur A, Morand C. Hesperidin displays relevant role in the nutrigenomic effect of orange juice on blood leukocytes in human volunteers: a randomized controlled cross-over study. PLoSOne. 2011; 6(11):e26669.

23. Zaragoza F, Fdez-Corbeira P, Iglesias I, Benedi J. New natural inhibitors of platelet aggregation in vivo. Part I. Citroflavonoids and hesperidin. An Real Acad Farm. 1986; 52: 497-504.

24. Son HS, Kim HS, Ju JS. Effects of rutin and hesperidin on total cholesterol concentration, transaminase and alkaline phosphatase activity in carbon tetrachloride treated rats. Hanguk Nonghwa Hakhoe Chi. 1991; 34: 318-326.

25. Galati EM, Monforte MT, Kirjavainen S, Forestieri AM, Trovato A, Tripodo MM. Biological effects of hesperidin, a citrus flavonoid. (Note I): antiinflammatory and analgesic activity. Farmaco 1994; 40(11):709-712.

26. Loguercio C, D'Argenio G, Delle cave M. Direct evidence of oxidative damage in acute and chronic phases of experimental colitis in rats. Dig Dis Sci. 1996; 41:1204-1211.

27. Tanaka T, Makita H, Kawabata K, Mori H. Chemoprevention of azoxymethane-induced rat colon carcinogenesis by the naturally occurring flavonoids, diosmin and hesperidin. Carcinogenesis 1997; 18: 957-965.

28. Kawaguchi K, Mizuno T, Aida K, Uchino K. Hesperidin as an inhibitor of lipases from porcine pancreas and Pseudomonas. Biosci Biotech Biochem. 1997; 61:102-104. DOI:10.1271/bbb.61.102. http://dx.doi.org/10.1271/bbb.61.102.

29. Kawaguchi K, Kikuchi S, Takayanagi K, Yoshikawa T, Kumazawa Y. Colony stimulating factor inducing activity of hesperidin. Planta Med. 1999; 65: 365-366.

30. Lee JH, Kim YS, Lee CK, Lee HK, Han SS. Antiviral activity of some flavonoids on Herpes-simplex virus. Korean Pharmacog. 1999; 30: 34-39.

31. Cho J. Antioxidant and neuroprotective effects of hesperidin and its aglycone hesperetin. Arch Pharm Res. 2006; 29(8):699-706.

32. Chen MC, Ye YI, Guang JI, Jian, Liu JW. Hesperidin upregulates heme oxygenase- 1 to attenuate hydrogen peroxide-induced cell damage in hepatic L02 cells. J Agric Food Chem. 2010; 58(6): 3330-3335.

33. Tamilselvam K, Braidy N, Manivasagam T, Essa MM, Prasad NR, Karthikeyan S, Thenmozhi AJ, Selvaraju S, Guillemin GJ. Neuroprotective effects of hesperidin, a plant flavanone, on rotenone-induced oxidative stress and apoptosis in a cellular model for Parkinson's disease. Oxidat Med cell Long. 2013.

34. Jagetia GC, Rao KVNM. Topical application of hesperidin, a citrus bioflavanone accelerates healing of full thickness dermal excision wounds in mice exposed to 6 Gy of whole body $\gamma$ Radiation. Clin Res Dermatol Open Access 2017; 4(3):1-8.
35. Jagetia GC, Rao KVNM. Hesperidin, a Citrus Bioflavonoid Potentiates Repair and Regeneration of Deep Dermal Excision Wounds of Mice Whole Body Exposed to Different Doses of 60Co $\gamma$-Radiation. Clin Dermatol J. 2018, 3(2): 000147.

36. Kawabe M, Tamano S, Shibata MA, Hirose M, Fukushima S, Ito N. Subchronic toxicity study of methyl hesperidin in mice. Toxicol Lett. 1993; 69:37-44.

37. Emim JA, Oliveira AB, Lapa AJ. Pharmacological evaluation of the anti-inflammatory activity of a citrus bioflavonoid, hesperidin, and the isoflavonoids, duartin and claussequinone, in rats and mice. J Pharm Pharmacol. 1994; 46(2):118-212.

38. Vabeiryureilai M, Lalrinzuali K, Jagetia GC. Determination of Anti-Inflammatory and Analgesic Activities of a Citrus Bioflavanoid, Hesperidin in Mice. Immunochem Immunopathol: Open Access. 2015;1(107):2.

39. Jain M, Parmar HS. Evaluation of antioxidative and antiinflammatory potential of hesperidin and naringin on the rat air pouch model of inflammation. Inflamm Res. 2011;60(5):483-491.

40. Crespo ME, Galvez J, Cruz T, Ocete MA, Zarzuelo A. Antiinflammatory activity of diosmin and hesperidin in rat colitis induced by TNBS. Planta Med. 1999; 65(07):651-653.

41. Sun YZ, Chen JF, Shen LM, Zhou J, Wang CF. Antiatherosclerotic effect of hesperidin in LDLr-/- mice and its possible mechanism. Eur J Pharmacol. 2017; 815:109-117.

42. Yeh CC, Kao SJ, Lin CC, Wang SD, Liu CJ, Kao ST. The immunomodulation of endotoxin-induced acute lung injury by hesperidin in vivo and in vitro. Life sciences. 2007; 80(20):182131.

43. Ho SC, Kuo CT. Hesperidin, nobiletin, and tangeretin are collectively responsible for the anti-neuroinflammatory capacity of tangerine peel (Citri reticulatae pericarpium). Food Chem Toxicol. 2014; 71:176-182.

44. Meng C, Guo Z, Li D, Li H, He J, Wen D, Luo B. Preventive effect of hesperidin modulates inflammatory responses and antioxidant status following acute myocardial infarction through the expression of PPAR- $\gamma$ and Bcl-2 in model mice. Molecular Med Rep. 2018;17(1):1261-1268.

45. Wang PH, Huang BS, Horng HC, Yeh CC, Chen YJ. Wound healing. J Chin Med Assoc. 2018; 81(2):94-101.

46. Rohl J, Zaharia A, Rudolph M, Murray RZ. The role of inflammation in cutaneous repair. Wound Practice \& Research: J Australian Wound Managem Assoc. 2015; 23(1):8.

47. Pinho-Ribeiro FA, Hohmann MS, Borghi SM, Zarpelon AC, Guazelli CF, Manchope MF, Casagrande R, Verri Jr WA. Protective effects of the flavonoid hesperidin methyl chalcone in inflammation and pain in mice: Role of TRPV1, oxidative stress, cytokines and NF- $\mathrm{KB}$. Chemico-Biol Interact. 2015; 228:88-99.

48. Hirata A, Murakami Y, Shoji M, Kadoma Y, Fujisawa S. Kinetics of radical-scavenging activity of hesperetin and hesperidin and their inhibitory activity on COX-2 expression. Anticancer Res. 2005; 25(5): 3367-3374.

49. Ghorbani A, Nazari M, Jeddi-Tehrani M, Zand H. The citrus flavonoid hesperidin induces p53 and inhibits NF- $\kappa B$ activation in order to trigger apoptosis in NALM-6 cells: involvement of PPAR $\gamma$-dependent mechanism. Eur. J. Nutr. 2012; 51(1): 39-46. 